\title{
Extreme Rainfall Variability in Australia: Patterns, Drivers, and Predictability*
}

\author{
ANDREW D. KING \\ ARC Centre of Excellence for Climate System Science, and Climate Change Research Centre, University of New South Wales, \\ Sydney, New South Wales, Australia \\ NichOLAS P. KLINGAMAN \\ National Centre for Atmospheric Science, and Department of Meteorology, University of Reading, Reading, United Kingdom
}

\section{Lisa V. AleXANDER AND MARKus G. DONAT}

ARC Centre of Excellence for Climate System Science, and Climate Change Research Centre, University of New South Wales, Sydney, New South Wales, Australia

\section{NiCOLAS C. JOURDAIN}

Climate Change Research Centre, University of New South Wales, Sydney, New South Wales, Australia

\section{PENELOPE MAHER}

ARC Centre of Excellence for Climate System Science, and Climate Change Research Centre, University of New South Wales, Sydney, New South Wales, Australia

(Manuscript received 23 November 2013, in final form 27 April 2014)

\begin{abstract}
Leading patterns of observed monthly extreme rainfall variability in Australia are examined using an empirical orthogonal teleconnection (EOT) method. Extreme rainfall variability is more closely related to mean rainfall variability during austral summer than in winter. The leading EOT patterns of extreme rainfall explain less variance in Australia-wide extreme rainfall than is the case for mean rainfall EOTs. The authors illustrate that, as with mean rainfall, the El Niño-Southern Oscillation (ENSO) has the strongest association with warmseason extreme rainfall variability, while in the cool season the primary drivers are atmospheric blocking and the subtropical ridge. The Indian Ocean dipole and southern annular mode also have significant relationships with patterns of variability during austral winter and spring. Leading patterns of summer extreme rainfall variability have predictability several months ahead from Pacific sea surface temperatures (SSTs) and as much as a year in advance from Indian Ocean SSTs. Predictability from the Pacific is greater for wetter-than-average summer months than for months that are drier than average, whereas for the Indian Ocean the relationship has greater linearity. Several cool-season EOTs are associated with midlatitude synoptic-scale patterns along the south and east coasts. These patterns have common atmospheric signatures denoting moist onshore flow and strong cyclonic anomalies often to the north of a blocking anticyclone. Tropical cyclone activity is observed to have significant relationships with some warm-season EOTs. This analysis shows that extreme rainfall variability in Australia can be related to remote drivers and local synoptic-scale patterns throughout the year.
\end{abstract}

\footnotetext{
* Supplemental information related to this paper is available at the Journals Online website: http://dx.doi.org/10.1175/JCLI-D-1300715.s1.

Corresponding author address: Andrew D. King, Climate Change Research Centre, Level 4, Mathews Building, University of New South Wales, Sydney NSW 2052, Australia.

E-mail: andrew.king@student.unsw.edu.au
}

\section{Introduction}

Rainfall in Australia is highly variable, both temporally and spatially, to a greater degree than in other countries and continents (Nicholls et al. 1997). This strong interannual variability is related to a variety of climate modes of variability, including the El Niño-Southern Oscillation (ENSO), Indian Ocean dipole (IOD), and the southern annular mode (SAM). We discuss here 


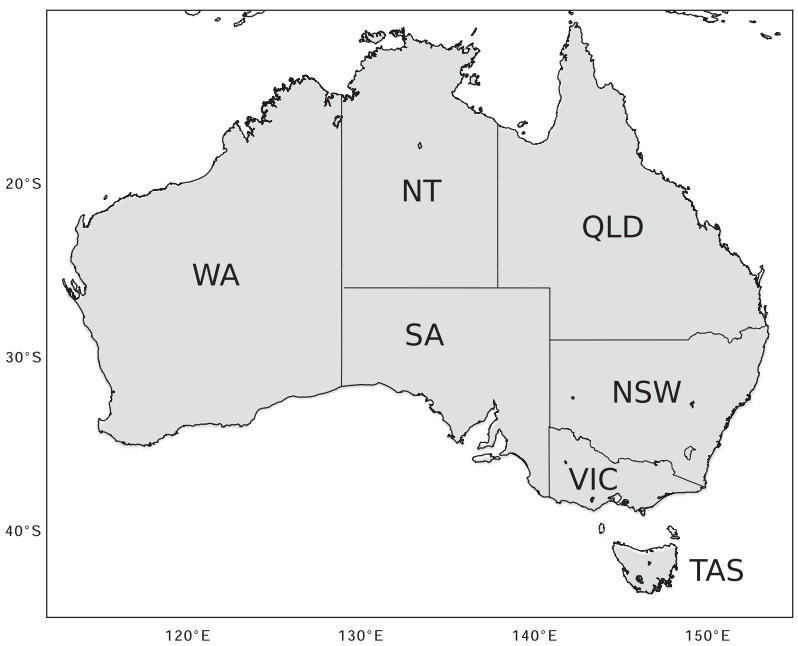

FIG. 1. Map of Australian states and territories referred to in this study. The abbreviations stand for the following states and territories: New South Wales (NSW), Northern Territory (NT), Queensland (QLD), South Australia (SA), Tasmania (TAS), Victoria (VIC), and Western Australia (WA).

relationships between these climate modes and Australian rainfall variability from previous literature. A map of the states and territories of Australia mentioned here is shown in Fig. 1.

The effects of ENSO on Australian rainfall variability are well documented (e.g., Allan 1988; McBride and Nicholls 1983; Nicholls et al. 1996). ENSO is generally considered to be the primary driver of rainfall variability in Australia. Rainfall in the east of Australia has the strongest relationship with ENSO (Risbey et al. 2009), where La Niña (El Niño) events are associated with increased (decreased) rainfall. ENSO also influences the summer monsoon, affecting rainfall patterns in northern Australia (Holland 1986). The position of the South Pacific convergence zone (SPCZ) is influenced by ENSO (Brown et al. 2011; Vincent et al. 2011), affecting rainfall patterns in northeast Australia and the locations of tropical cyclogenesis (Vincent et al. 2011). The ENSOrainfall relationship is nonlinear across Australia generally (Power et al. 2006) and within specific regions such as southeast Queensland (Cai et al. 2010) and southeast Australia (King et al. 2013c), whereby the impact of ENSO on rainfall during La Niña events is stronger than during El Niño events.

The IOD primarily modulates rainfall on interannual time scales in western and southern Australia during winter and spring (Risbey et al. 2009). The IOD is also related to the climate of southeast Australia (Meyers et al. 2007) and has been linked to droughts in this region (Ummenhofer et al. 2009; Ummenhofer et al. 2011).
Unlike ENSO and the IOD, SAM is an extratropical mode that reflects variability in the Southern Hemisphere midlatitude storm tracks (Marshall 2003). Consequently, it is associated with rainfall in southern Australia, such as southwest Western Australia and parts of southeast Australia (Meneghini et al. 2007; Risbey et al. 2009). The SAM is also related to spring rainfall in Queensland and New South Wales through teleconnections with weather systems located over the Tasman Sea (Hendon et al. 2014; Risbey et al. 2009). A positive trend in the SAM in recent decades has been associated with the rainfall decline in southwest Western Australia (Cai and Cowan 2006; Meneghini et al. 2007). Other studies suggest a weaker teleconnection between SAM and southwest Western Australia rainfall (Feng et al. 2010).

Several studies have considered how some of these remote drivers relate to mean and extreme rainfall variability in Australia as a whole (e.g., Risbey et al. 2009; Min et al. 2013) and within particular regions of the continent (e.g., Gallant et al. 2012; Klingaman et al. 2013). The relative roles of these remote drivers are examined in this study.

Australian climate is also influenced by many local drivers. Atmospheric blocking to the southeast of Australia is known to increase rainfall over much of Australia, particularly during the cool season (Risbey et al. 2009). The position and intensity of the subtropical ridge influences rainfall in the east of Australia (Cai et al. 2011; Timbal and Drosdowsky 2013; Whan et al. 2014). An important consideration when investigating the effects of these remote and local drivers on Australian climate is the lack of independence between drivers.

Weather and climate regimes vary across Australia. The north of the country has a tropical and subtropical climate with the majority of rainfall concentrated during the summer months. Monsoon depressions and tropical cyclones are the major rain-bearing systems in this region. The extratropical south of Australia is affected by midlatitude frontal systems. East coast lows affect the coasts of Victoria and New South Wales, bringing rainfall in winter primarily. The south and southwest experience more rainfall in winter, whereas, in the southeast rainfall is more consistent throughout the year. These weather systems are affected by the remote and local drivers described previously in complex and sometimes conflicting ways, complicating the study of rainfall variability in Australia.

The effects of these modes of variability and different weather systems on continental and regional rainfall have been studied to some degree. However, there has been less focus on the relationships between climate drivers and extreme rainfall. Therefore, further analysis 
of the associations between rainfall and different climate modes is required. These relationships may well differ from those that have been studied previously for mean rainfall. Extreme rainfall has the greatest impact on people and the environment. Very heavy rainfall can lead to severe floods, such as those of 2010/11 that devastated large areas of Queensland. Improving our understanding of the regional effects of drivers of extreme rainfall would be beneficial and may lead to improved seasonal predictability of flooding. For example, it is understood that extreme rainfall is heavier during $\mathrm{La}$ Niña events than in neutral or El Niño events (e.g., King et al. 2013a). However, there are gaps in our scientific understanding of how teleconnections between ENSO (and other climate drivers) and extreme rainfall vary monthly and seasonally.

A limited number of studies have examined the statistical relationships between modes of variability and extreme rainfall in Australia, but few have considered physical mechanisms. Min et al. (2013) examined the statistical relationships between ENSO, SAM, and the IOD with extreme rainfall, calculated using extreme value statistics. Strong relationships exist between ENSO and extreme rainfall in eastern Australia with multidecadal modulation related to the interdecadal Pacific oscillation (IPO) (King et al. 2013a).

This study aims to analyze patterns of extreme rainfall variability across Australia and relationships with mean rainfall, climate modes of variability, and the activity of several weather system types. Comparisons are made between results for extreme and mean rainfall to examine differences in relationships. Predictability of extreme (and mean) rainfall patterns is also considered in this study.

A brief description of the data used and the methods applied is outlined in section 2 (more details on the methodology can be found in the supplementary material). Results are presented for each climate driver or weather system type and are described in section 3. A discussion of the results and the conclusions is given in section 4 .

\section{Data and methods}

The observational monthly total and extreme precipitation data used in this study were calculated from the Australian Water Availability Project (AWAP) gridded dataset of daily rainfall (Jones et al. 2009). The AWAP dataset runs from 1900 to the present and grids all available station data on a particular day on to a $0.05^{\circ}$ grid. The data were regridded to a $0.5^{\circ}$ resolution for computational reasons. The impacts of using data of different horizontal resolutions were tested and found to have minimal effects on the results. As an aim of the study was to look at spatial variability of total and extreme rainfall, a gridded product was deemed more appropriate than station data. Over most of Australia, AWAP captures extreme rainfall variability, however, in some rural areas, where the station network is sparse, the gridded data have spurious trends (King et al. 2013b); therefore, a mask was applied. For our study, areas of Australia where AWAP has any missing values during the analysis period were masked. To limit issues of variability in the station network used to generate AWAP, analysis was limited to 1930-2011. Prior to 1930, there were fewer stations used in the calculation of the AWAP daily rainfall grids (Jones et al. 2009). Results found using AWAP were evaluated against those using other rainfall datasets (see supplementary material for more details).

In this study, extreme rainfall is defined using the monthly maximum consecutive 5 -day precipitation totals (Rx5day). This is an extreme rainfall index recommended by the Commission for Climatology (CCI)/ Climate Variability and Predictability (CLIVAR)/Joint Technical Commission for Oceanography and Marine Meteorology (JCOMM) Expert Team on Climate Change Detection and Indices (ETCCDI; Zhang et al. 2011). The total rainfall and Rx5day index were calculated for each $0.5^{\circ}$ grid box in each month of the 82-yr period. Only AWAP grid boxes where the time series of the total rainfall and Rx5day index were complete (i.e., with no missing data) were used in this investigation.

To examine spatial and temporal variability in the monthly rainfall and Rx5day across Australia, an empirical orthogonal teleconnection (EOT; Van den Dool et al. 2000) method was applied. (A detailed description of the method and its verification is in the supplementary material section.) In short, EOT analysis statistically decomposes the (extreme) rainfall fields into orthogonal (in time) time series related to the spatial points that explain the greatest space-time variance in the domain (as measured by correlation coefficients with all other grid boxes). That is, there is one grid point (referred to as the base point) that is associated with the greatest amount of variance across all other grid points. The orthogonality of the EOTs allows for the investigation of multiple drivers of Australian (extreme) rainfall variability beyond the primary driver. EOTs are only orthogonal in either time or space, whereas empirical orthogonal functions (EOFs) are orthogonal in both time and space, making the physical interpretation of EOTs simpler than EOFs. We calculate EOTs that are orthogonal in time. A modified EOT method (Smith 2004) using the all-Australia mean (and extreme) rainfall time series, as opposed to the global variance, was 
applied. Use of the global variance biases results to regions of higher rainfall totals. The modified EOT method applied in this study more naturally lends itself to studying mean (and extreme) rainfall variability.

As many EOTs can be computed as are desired (up to the number of grid boxes in the domain). After the first EOT, the calculation is repeated on residual time series that remove, by linear regression, the effects of EOTs calculated previously. The first four EOTs were calculated separately for each calendar month of the 1930-2011 time series for Rx5day and total rainfall to allow for the investigation of several extreme and mean rainfall patterns across different regions of Australia. EOTs were also calculated using seasonal data, but these EOTs missed some details that were better captured with monthly analysis, such as the annual cycle of the ENSO influence on extreme rainfall.

\section{a. Indices for remote drivers}

Indices for several climate drivers were used to examine statistical relationships with EOTs. ENSO is represented by the Southern Oscillation index (SOI) and the Niño-3.4 SST index, so that both atmospheric and oceanic indices were considered. The SOI was calculated as the difference in standardized mean sea level pressure between Tahiti and Darwin (Trenberth 1984). The Niño3.4 index was calculated from the Hadley Centre Sea Ice and Sea Surface Temperature dataset (HadISST) as an SST-based index of ENSO (Rayner et al. 2003). The IOD is represented by the dipole mode index (DMI; Saji et al. 1999) also calculated from HadISST. The DMI was both correlated and partially correlated (removing ENSO influence) with EOTs. The SAM index (SAMI) is that of Marshall (2003) and was calculated using stationbased data as the difference in pressure between $40^{\circ}$ and $65^{\circ} \mathrm{S}$ (Gong and Wang 1999). The relationship between the SAM and the EOTs was examined for the 1957-2011 period of reliable SAM data (Marshall 2003). (Time series of the indices described here are shown in Fig. S1 of the supplementary material.)

Relationships between the IPO and EOT time series were also analyzed as previous studies have found relationships between the IPO and total (Power et al. 2006; Klingaman et al. 2013; Speer 2008; Speer et al. 2011) and extreme rainfall (King et al. 2013a) in parts of eastern Australia particularly. All correlations between an index for the IPO (Parker et al. 2007) and EOT time series were found to be nonsignificant after reduction in the number of degrees of freedom to account for serial interannual persistence in the IPO. The Madden-Julian oscillation (MJO; Madden and Julian 1971) is an important driver of Australian rainfall variability. The MJO was not considered in this study as it is an intraseasonal mode of variability which would require (extreme) rainfall indices at a daily or weekly resolution as opposed to the monthly indices applied in this study.

To examine the physical mechanisms behind mean and extreme rainfall variability, reanalysis fields were used. The Twentieth-Century Reanalysis (20CR; Compo et al. 2011) extends farther back in time than other reanalysis products, to 1871 (before the start date of this study's analysis). The reanalysis was generated through using an atmosphere-only model constrained by observed surface pressure, sea surface temperatures (SSTs), and sea ice. An ensemble of 56 members was generated using an ensemble Kalman filter data assimilation technique. King et al. (2013a) found that the 20CR ensemble members captured the observed ENSOextreme rainfall relationship in eastern Australia, suggesting that it performs reasonably well in this region. Ensemble-mean 20CR fields have been used to examine Queensland rainfall variability (Klingaman et al. 2013) and climate variability in southeast Australia (Ashcroft et al. 2014). The 20CR fields used in this study are outgoing longwave radiation, mean sea level pressure (MSLP), zonal and meridional winds, and specific humidity. All 20CR data used here have a monthly resolution and are the ensemble-mean fields.

\section{b. Indices for local drivers}

Indices calculated from the 20CR (for the period 1930-2010) were also used to represent variability in large-scale systems that affect Australian weather. The atmospheric blocking index (BI) was calculated using 20CR 500-hPa zonal winds (Pook and Gibson 1999). For points along $140^{\circ} \mathrm{E}$, the $\mathrm{BI}$ is defined as

$$
\mathrm{BI}=0.5\left(U_{25}+U_{30}-U_{40}-2 U_{45}-U_{50}+U_{55}+U_{60}\right),
$$

where $U_{x}$ is the monthly-mean zonal wind at each latitude $x$ in the Southern Hemisphere.

Indices for the position and the intensity of the subtropical ridge (STR-P and STR-I, respectively; Larsen and Nicholls 2009) were calculated from 20CR MSLP by cubic spline fitting of the zonally averaged MSLP across the Australian domain $\left(10^{\circ}-50^{\circ} \mathrm{S}, 110^{\circ}-155^{\circ} \mathrm{E}\right)$. The maximum of the spline fit gives the STR-I index, and the latitude at which the maximum occurs gives the STR-P.

The position of the western portion of the South $\mathrm{Pa}$ cific convergence zone (SPCZ) is represented by an index (SPCZ-I; Vincent et al. 2011). This index was calculated from $20 \mathrm{CR}$ precipitation as the latitude of maximum zonally averaged precipitation between $155^{\circ}$ and $175^{\circ} \mathrm{E}$.

Indices for tropical cyclone frequency were also calculated using observed tracks from the International 
Best Track Archive for Climate Stewardship (IBTrACS) dataset (Knapp et al. 2010). Monthly indices of cyclone frequency (TC-E and TC-W for eastern and western regions, respectively) were calculated by counting the number of cyclones per day that pass through two defined regions (shown in Fig. 5) in each month of the warm season (November-April) from 1930 to 2010. (The time series of these local indices are also shown in Fig. S1 of the supplementary material.) All indices were correlated or partially correlated (removing ENSO using the Niño-3.4 index) with EOT time series. Correlations (Spearman's rank) are defined as statistically significant at the $5 \%$ level ( $p$ value $<0.05$ ). Given that correlations are calculated between each climate index and 96 EOTs (four for each calendar month for both total and extreme rainfall) and the 5\% significance level applied, approximately five of these correlations would be expected to be significant by chance for each climate mode. Therefore, caution needs to be exercised in the analysis based on these correlation coefficients.

All correlations between climate indices and the EOT time series are Spearman's rank. This is because several indices, including the tropical cyclone indices, are not normally distributed. Nevertheless, tests showed high agreement between Pearson's and Spearman's rank correlation coefficients for the majority of climate indices. The fields were correlated with and regressed onto individual EOTs to produce maps.

\section{Results}

\section{a. EOT correlation maps}

The EOTs were calculated for the Rx5day index (and total rainfall) for each month of the year over 1930 2011. The base point of an EOT is the grid point which has the time series that explains the most variance in time series at other points. Correlating the base-point time series of each EOT with the time series at other grid points gives an idea of the spatial variance in extreme (and total) rainfall. Maps of these correlation coefficients were plotted for each EOT. Examples for the leading EOTs of January and August extreme and mean rainfall are shown in Fig. 2.

The locations of the base points of the leading EOTs shift seasonally for both extreme and total rainfall (Fig. 2 and Fig. S2 of the supplementary material). The base points for extreme and total rainfall are in similar locations during the warmer months, in the north and northeast of Australia. In the cooler months, the locations of leading Rx5day EOTs tend to move poleward but more so for total rainfall. This is particularly clear in August (Fig. 2 and Fig. S2c) and October (Fig. S2e), where the leading total rainfall EOTs are in Victoria and southeast (SE) New South Wales, respectively. Although, in other cool-season months, such as July (Fig. S2b) and September (Fig. S2d), the leading EOTs of extreme and total rainfall are in similar locations. However, the second-order EOTs of total rainfall in July and September are located much farther south than those of extreme rainfall. There is greater variability in the locations of lower-order EOTs generally.

All of the 48 extreme rainfall EOT base points (4 EOTs for each of 12 months) are on mainland Australia; however, 3 cool-season EOTs of monthly total rainfall are located on Tasmania. The total space-time variance associated with the first four EOTs varies from month to month but has a stronger seasonal cycle for extreme rainfall than for total rainfall (Fig. S3 and Tables S1, S2 of the supplementary material). In the cool season there appears to be greater spatial homogeneity in extreme rainfall than in the warm season, with more widespread coherent extreme rainfall patterns. In all months there is lower variance in extreme rainfall explained by the four leading extreme rainfall EOTs than total rainfall variance explained by the first four total rainfall EOTs.

The space-time variance associated with each Rx5day EOT is between $8 \%$ and $22 \%$ for each leading EOT and decreases for lower-order EOTs to a minimum of roughly $4 \%$ when studying at the first four EOTs for each month. These values are lower than those found for monthly total rainfall, and considerably lower than those found with EOTs of seasonal rainfall in Queensland (Klingaman et al. 2013) and annual rainfall nationally (Smith 2004). One possible explanation for this may be increased inhomogeneities in monthly extreme rainfall as opposed to monthly, seasonal, and annual total rainfall, leading to less coherent variability. Also, the Australia domain examined in this study is large compared with Queensland [the focus of Klingaman et al. (2013)]. Explained variance would be expected to decrease with increases in domain size as different areas of Australia have different relationships between modes of variability and extreme rainfall. Smith (2004) found the leading EOT of annual rainfall, located in southwest Queensland, was associated with $60 \%$ of variance. A similar calculation of the leading annual rainfall EOT in AWAP, with a mask applied, found this EOT to be located farther northeast and associated with only $25 \%$ of space-time variance across Australia (not shown). However, Smith (2004) used the SILO gridded dataset (Jeffrey et al. 2001) without the application of a mask through central areas of Australia, where there are few rainfall stations. In these areas, oversmoothing of rainfall data would likely lead to strong similarity in rainfall 

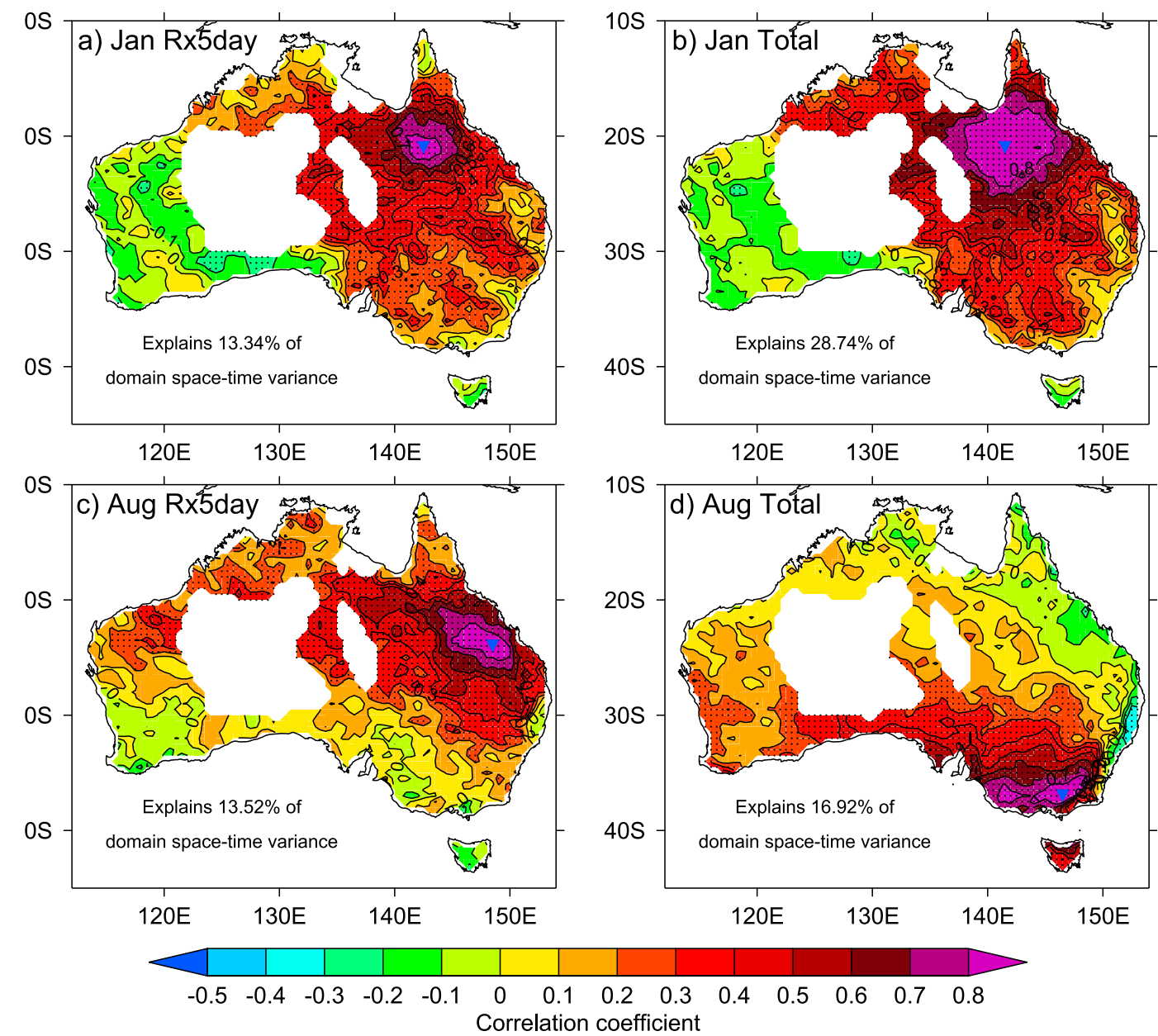

FIG. 2. Maps of the locations of leading EOTs (blue triangles) and the correlations between EOT time series (i.e., base-point time series) and time series at all other grid points for (a) January Rx5day, (b) January total rainfall, (c) August Rx5day, and (d) August total rainfall. Stippling indicates where the correlations are significant at the 5\% level. White areas over Australia indicate masking where there is at least one missing data point in the time series. time series of neighboring grid boxes and artificial increases in the variance explained by leading EOTs. In this study a mask is applied where any values of the Rx5day index or monthly total rainfall are missing (see white areas on maps in Fig. 1) causing small variations in the EOT coverage between months. Generally, areas of central and inland Western Australia are masked in this analysis.

Many Rx5day EOTs have extreme rainfall signatures across reasonably large areas of the continent extending hundreds of kilometers from the base point. This would suggest that, at least for maximum consecutive 5-day rainfall, large-scale processes dominate and drive where locally strong convective rainfall occurs. Isolated convective systems are less likely to produce rainfall amounts that would be detected at more than a small number of stations (or any at all in some central parts of Australia) and therefore are less likely to feature in the EOT correlation maps. Tests on EOTs of maximum 1-day rainfall (Rx1day) indicated greater spatial inhomogeneities in "more extreme" extreme rainfall variability.

\section{b. Trends in EOT time series}

Linear trends were calculated for each of the EOT time series for mean and extreme rainfall. Only 1 of 48 extreme rainfall EOTs has a significant trend at the 5\% level (March EOT2). This is fewer than would be expected by chance (2.4). This lack of significant trends is in agreement with the findings of other studies (e.g., Haylock and Nicholls 2000; Alexander et al. 2007; Gallant et al. 2007) where few areas of Australia are observed to exhibit significant trends in extreme rainfall. Although, Speer (2008) detected significant decreases in extreme annual east coast rainfall during the second half of the twentieth century. This trend may not be detected in our analysis because it could map onto more than one EOT. Also, the trend may be nonsignificant for our (longer) period of study. 
More total rainfall EOT time series have significant increasing trends ( 6 of 48). All of these EOTs are located in either the Northern Territory or Queensland and occur during the warm season. No EOT time series have significant decreasing trends. This is consistent with trends shown on the Bureau of Meteorology website (available at http://www.bom.gov.au/climate/change/index.shtml\#tabs= Climate-change-tracker\&tracker $=$ trend-maps) for the 1930-2012 period. Other studies show different trends when different periods are examined or if station data are used (e.g., Gallant et al. 2007).

\section{c. Relationships between remote drivers and EOTs}

Indices representing three prominent modes of variability (ENSO, IOD, and SAM) were correlated with each EOT time series to examine the roles of the different potential drivers in extreme (and total) rainfall variability for different areas of Australia. Relationships involving total rainfall EOTs are only discussed when they are distinctly different from results based on extreme rainfall. (The EOTs and corresponding correlation coefficients are shown for Rx5day and total rainfall in Tables S1 and S2 of the supplementary material, respectively.) Maps of the normalized regression coefficients of 20CR fields were also plotted, and a selection of these is shown. Many of these maps show signatures that resemble patterns typically associated with the climate drivers studied.

\section{1) ENSO}

The relationship between ENSO and each EOT was investigated using the SOI and the Niño-3.4 SST index. The SOI has significant positive correlations with 10 of the 12 leading Rx5day EOTs (all but January and June). This suggests La Niña (El Niño) events are associated with higher (lower) values of extreme rainfall in northern and eastern Australia in general. The correlations are weakest in winter when ENSO events are usually not yet developed or are already terminated. There are significant positive correlations in some months with lower-order EOTs located in northern and eastern areas of Australia. The Niño-3.4 index correlations largely reflect the relationships between SOI and the EOTs with all significant correlations being negative. Although, the SST signature associated with ENSO is weaker during the autumn and early winter, so relationships between the Niño-3.4 index and EOTs are generally nonsignificant at this time of year.

The total rainfall EOTs also show strong relationships with ENSO. The SOI and Niño-3.4 index generally have slightly larger correlations with the total rainfall EOTs than the extreme rainfall EOTs but have a similar seasonal cycle.
The ENSO relationship with many EOTs can be seen in several of the regression fields. Regressing MSLP on to the leading EOTs of December extreme and total rainfall (Figs. 3a,b) produces similar patterns of lower pressure over the Maritime Continent and higher pressure over the central equatorial Pacific. This reflects the well-known enhanced Walker-like circulation pattern which increases extreme (and total) rainfall amounts over northeastern areas of Australia in particular. Heavier rainfall totals in these EOT time series are also associated with the typical ENSO SST pattern: warmer SSTs in the western equatorial Pacific and locally to the Australian region and cooler SSTs in the central and eastern equatorial Pacific (Figs. 3c,d). Wetter-than-average conditions in many extreme and mean rainfall EOTs are associated with La Niña-like SST patterns and warm local SSTs off the coast of northeast Australia. Previous research has pointed to the important role of locally warm SST anomalies around northern Australia in warm-season heavy rainfall events (Evans and Boyer-Souchet 2012). Regressing outgoing longwave radiation (OLR) on to the December EOT1 time series of extreme and total rainfall (Figs. 3e,f) also produces recognizable patterns one might relate to the ENSO phenomenon, such as an intensification of the SPCZ near Queensland associated with increased extreme rainfall.

As the position of the western pole of the SPCZ is strongly correlated to the Niño-3.4 index (Vincent et al. 2011), we also discuss here results using the SPCZ index. The SPCZ is related to some extreme rainfall variability in the north and east of Australia. The SPCZ index has few significant correlations with Rx5day EOTs (4 of 48). These are negative correlations, implying that increased extreme rainfall occurs when the western pole of the SPCZ is in a southerly position. Some 20CR fields show an SPCZ-like signature being projected onto several EOTs (e.g., Figs. 3e,f). This is particularly well observed when the OLR field is regressed on to warm-season EOTs centered in Queensland. The interannual variability of the summer SPCZ signal is tightly related to the ENSO phenomenon.

In summary, ENSO is a major driver of extreme (and total) rainfall, particularly in the east of the country and during the austral warm season. We observe shifts in the SPCZ related to ENSO and affecting the northeast of Australia. These findings are in agreement with several other studies (Risbey et al. 2009; King et al. 2013a; Min et al. 2013), but they are reached using different methods.

\section{2) IOD}

The IOD is also related to extreme rainfall variability in Australia. Seven out of 48 Rx5day EOTs are significantly correlated to the DMI (Table S1 of the 

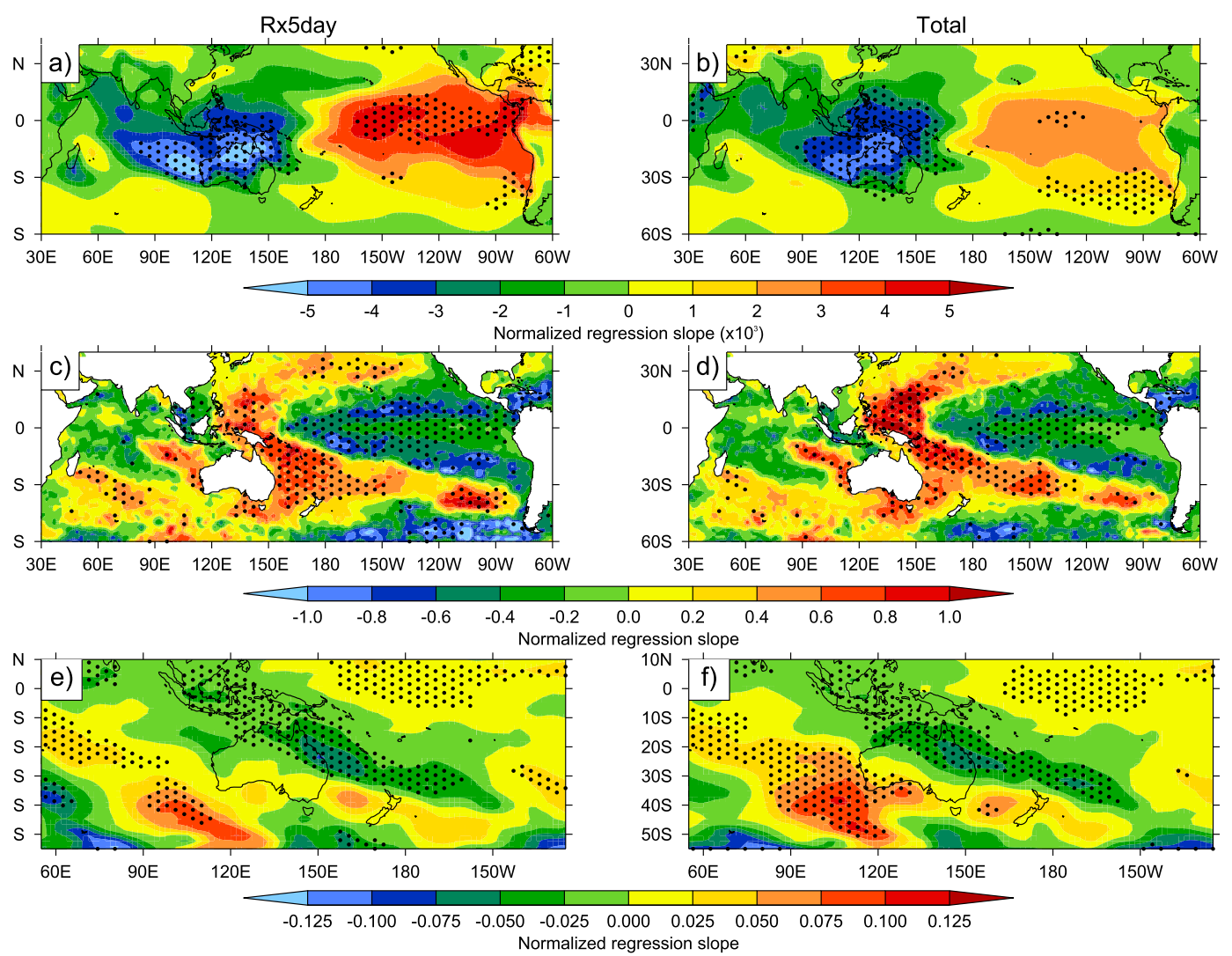

FIG. 3. Maps of (a),(b) MSLP; (c),(d) SSTs; and (e),(f) OLR regressed on to December EOT1 of (left) Rx5day and (right) total rainfall. Stippling indicates $5 \%$ significance in the correlation coefficients.

supplementary material). Most of these are EOTs for extreme rainfall in late autumn to late spring and located in eastern Australia with negative correlations with the DMI. A similar pattern can be observed with the EOTs of total rainfall. The predominance of winter and spring relationships between the IOD and Australian rainfall EOTs is in agreement with previous studies (e.g., Risbey et al. 2009). Removing the ENSO effect (through partial correlations with Niño-3.4) reduces the number of significant relationships (to five for Rx5day EOTs) but not greatly. This illustrates that the IOD relationships with EOTs are probably not statistical artifacts resulting from the ENSO-EOT relationships (assuming all relationships are linear). Warmer SSTs in the eastern Indian Ocean promote wetter conditions in mainland eastern Australia in spring time particularly. Several significant positive correlations exist between the IOD and late summer extreme rainfall EOTs in inland eastern Australia. However, these relationships do not extend to total rainfall.

\section{3) SAM}

Four of 48 Rx5day EOTs have significant positive correlations with the SAM index (close to the number that might be expected by chance statistically). Nine total rainfall EOTs are significantly correlated with SAM. The majority are positive correlations, although significant negative correlations are observed with total rainfall EOTs in Tasmania. Most EOTs which are associated with the SAM are located in southeastern Australia. Several of these EOTs in SE Australia are also associated with higher MSLP over the Tasman Sea and onshore flow over the coastlines of New South Wales and southern Queensland. We find several wintertime SAM-EOT relationships, whereas Maher and Sherwood (2014) showed nonsignificant relationships between SAM and rainfall at this time of year. EOTs with significant SAM relationships also have strong associations with atmospheric blocking south of Australia and the position and intensity of the subtropical ridge (Tables S2, S4 of the supplementary material). Cowan et al. (2013) found springtime relationships between positive SAM and enhanced blocking resulting in increased rainfall in SE Australia. Some extreme rainfall EOT time series with significant positive SAM index correlations also have relationships with ENSO indices and Walker-like circulation patterns. 


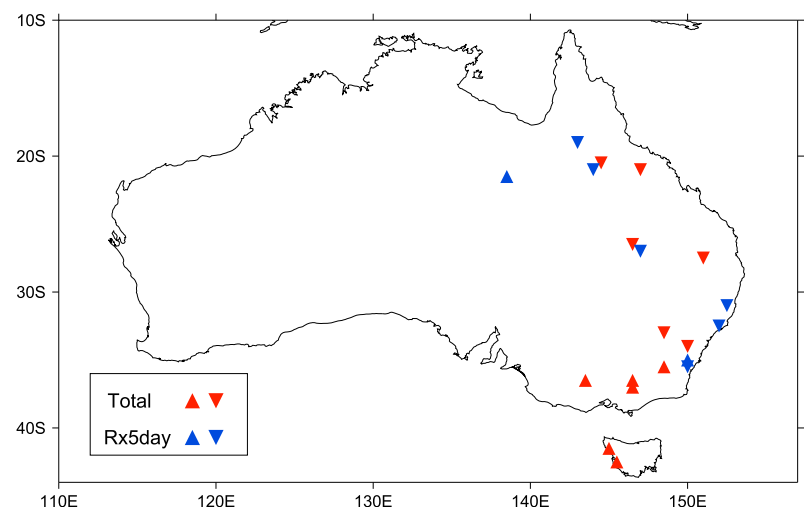

FIG. 4. Map of the locations of significant correlations (at the 5\% level) between the subtropical ridge position index and EOT time series. Positive and negative correlations are indicated by the upward and downward pointing triangles, respectively.

\section{d. Relationships between local drivers and EOTs}

Indices representing several local drivers (blocking, subtropical ridge, and tropical cyclones) were also correlated with each EOT time series. (The EOTs and corresponding correlation coefficients are shown in Tables S3 and S4 of the supplementary material.) Maps of the normalized regression coefficients of 20CR fields on to EOTs were also plotted. It is worth noting that these local drivers are not independent of the remote drivers discussed previously.

\section{1) BLOCKING}

The relationships between blocking and extreme rainfall variability were examined first by correlating each Rx5day EOT with the BI. Of the 48 Rx5day EOTs,
13 have significant correlations with the BI: 11 of these positive. The majority of significant correlations between the BI and EOTs occur in the cool season.

There are many more significant relationships between blocking and total monthly rainfall than extreme rainfall. Twenty-one of the total rainfall EOTs have statistically significant correlations with the BI. The blocking influence extends throughout the year but is weakest in autumn. The EOTs in mainland SE Australia have positive correlations with the BI, whereas those in the Northern Territory and Tasmania have negative correlations where significant. Risbey et al. (2013) found enhanced blocking is related to an increase in cutoff low systems affecting southeast Australia bringing rainfall to this region.

Signatures of blocking are seen in some of the atmospheric fields from the 20CR. As would be expected, higher values of the BI coincide with EOTs that are associated with increased MSLP south of Australia. Enhanced blocking is related to increased cloudiness in SE Australia, particularly as seen through fields of the OLR regressed on to EOTs. Onshore moist flow along the coast of SE Australia is a feature of EOTs where blocking increases extreme rainfall amounts.

The blocking index (Pook and Gibson 1999) used here is calculated using winds over the $140^{\circ} \mathrm{E}$ meridian while the center of blocking is more commonly farther east over the Tasman Sea. Using a different blocking index centered farther east would likely lead to fewer significant correlations with EOTs in the Northern Territory and have little effect on results in eastern Australia. Cowan et al. (2013) found blocking at different meridians $\left(130^{\circ}\right.$ and $\left.140^{\circ} \mathrm{E}\right)$ had slightly different associations with precipitation patterns. Klingaman et al. (2013)
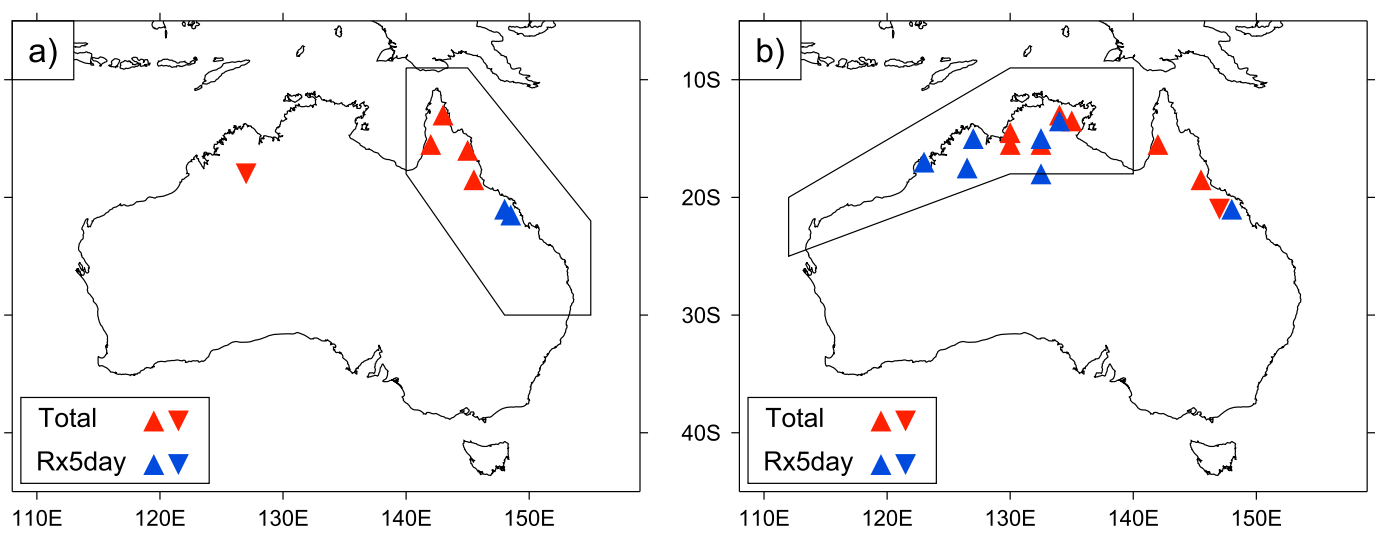

FIG. 5. Maps of the locations of Rx5day (blue) and total rainfall (red) EOTs correlated at the 5\% level with the (a) TC-E and (b) TC-W indices. Positive and negative correlations are indicated by the upward and downward pointing triangles, respectively. The polygons in (a),(b) represent the areas for which tropical cyclone counts are calculated for TC-E and TC-W indices, respectively. 
found small differences in the relationships between Queensland seasonal rainfall EOTs and blocking at different longitudes between $120^{\circ} \mathrm{E}$ and $180^{\circ}$.

\section{2) SubtropicAl RIDGE}

Six Rx5day EOTs have significant negative correlations with the STR-P index (Fig. 4). When the STR is in an anomalously poleward position there is an associated increase in extreme rainfall in New South Wales and Queensland. The position of the ridge is most strongly related to Eastern Australia extreme rainfall variability from late winter to early summer. The trajectories of rain-bearing systems are influenced by the position of the STR.

The STR position is more strongly related to mean rainfall variability than extreme rainfall variability. Six EOTs of total rainfall have significant positive correlations with STR-P, located in Tasmania, Victoria, and southern New South Wales (Fig. 4). Six EOTs centered farther north have significant negative correlations with STR-P.

The position of the STR (or the associated subtropical jet) has previously been related to the IPO, SAM, and blocking (e.g., Speer 2008; Kidston et al. 2009; Maher and Sherwood 2014), illustrating the complex nature of investigating the drivers of rainfall patterns in the Australian region. While the ridge position has strong correlations with rainfall in eastern Australia, these correlations may be the result of covariability with other climate drivers.

The STR-I index also has significant relationships with EOTs ( 7 for Rx5day and 11 for total rainfall). The intensity index is, in general, negatively correlated with the EOT time series. Thus, a weaker ridge is associated with increased (extreme) rainfall for sites primarily in eastern Australia.

\section{3) Tropical CyClones}

The monthly TC-E and TC-W indices (see section 2) were calculated for boxes to the northeast and northwest of Australia, respectively (Figs. 5a,b). Each TC index is rank correlated with November-April monthly EOTs of extreme and total rainfall. Seven of $24 \mathrm{Rx} 5$ day EOTs are significantly positively correlated to the TC-W index, indicating that an increased frequency of TCs passing through the box is related to increased extreme rainfall; 6 of these EOTs are located in northern Western Australia or the Northern Territory. The leading EOT in December, centered in eastern Queensland, has a significant positive correlation with TC-W but also with TC-E. There are only two significant correlations between TC-E and the Rx5day EOTs, both of which are positive and located in the east of Queensland.

Eight of 24 mean rainfall EOTs have significant correlations with TC-W. These are mostly positive correlations and
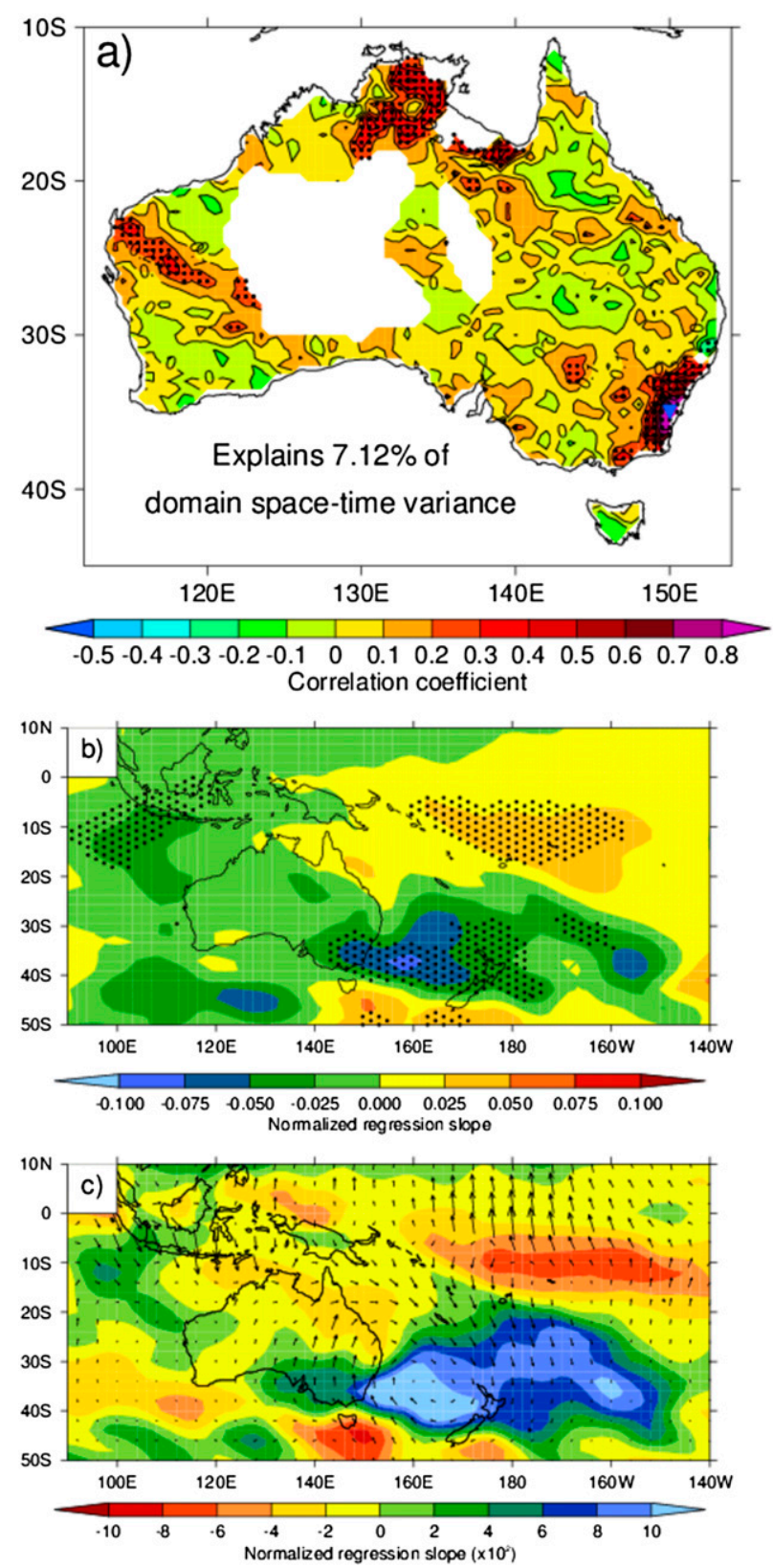

FIG. 6. (a) Map of the location of the August Rx5day EOT3 (blue triangle) and the correlations between EOT time series and all other residual time series. Stippling indicates where the correlations are significant at the $5 \%$ level. White areas over Australia indicate masking where there is at least one missing data point in the time series. (b) Map of OLR regressed on to August Rx5day EOT3. Stippling indicates where the correlation coefficients are significant at the $5 \%$ level. (c) Map of $850-\mathrm{hPa}$ moisture and winds (arrows) regressed on to August Rx5day EOT3.

for EOTs located in Western Australia and the Northern Territory. There are five significant correlations between TC-E and total rainfall EOTs: four of which are positive and for EOTs in Queensland. Klingaman et al. (2013) 

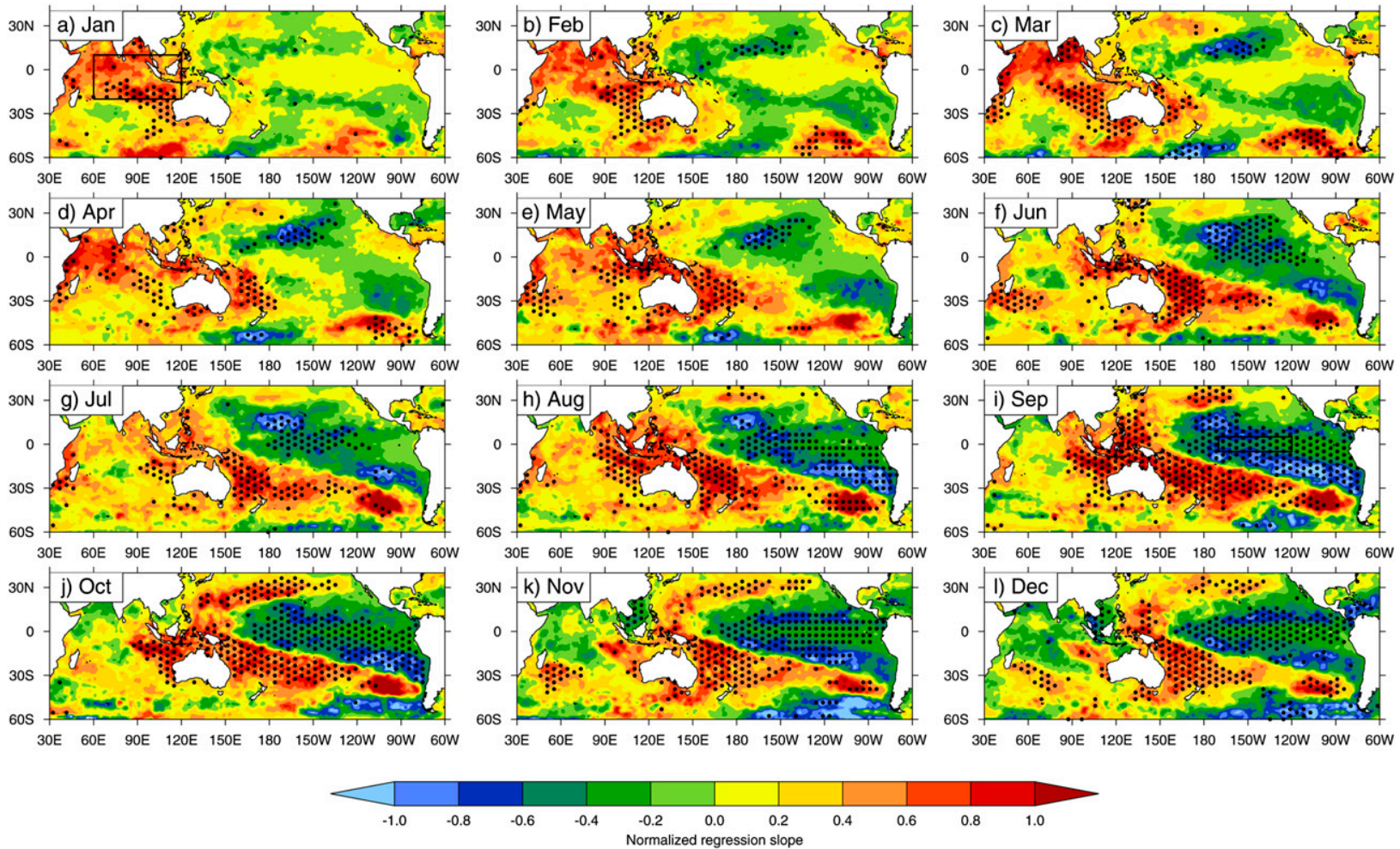

FIG. 7. Maps of SSTs from each calendar month (a)-(1) from January to December regressed on to December Rx5day EOT1. The boxed region in (a) is used to calculate mean January SSTs in the equatorial Indian Ocean to examine relationships with the EOT. The boxed region in (i) is used to calculate September Niño-3.4 region SSTs. Stippling indicates 5\% significance of the correlation between SSTs and the EOT.

also found significant relationships between Coral Sea tropical cyclones and summer rainfall in northern Queensland. Our results contrast somewhat with Lavender and Abbs (2013), who found that closed-low systems (including tropical cyclones) contributed more to extreme rainfall totals than total rainfall.

\section{4) EAst COAST LOWS}

The relationships between east coast lows (ECLs) and extreme rainfall variability were studied through the use of 20CR fields: that is, without the formation of an index to describe their frequency, locations, or intensities. Several EOTs during the cool season have base points on the coast of New South Wales, with strong correlation patterns to the east of the Great Dividing Range extending along the coast of SE Australia. Figure 6a shows the EOT correlation map for August Rx5day EOT3 as an example. ECLs have similar rainfall signatures, with the heaviest precipitation occurring along the coastal fringe. Some general patterns emerge in the atmospheric circulation associated with these EOTs. Increased cloud cover over the immediate area around the location of the EOT and extending into the Tasman
Sea to the east can be observed in the OLR fields (Fig. 6b). There are also clearer skies to the south and often positive correlations with the blocking index. These EOTs are generally linked with anomalously high moisture availability over the Tasman Sea and southwest Pacific and anomalous cyclonic circulation (Fig. 6c), patterns that would be associated with east coast lows.

\section{e. Predictability of extreme rainfall}

While it is useful to advance our understanding of the drivers of extreme rainfall events, it is perhaps of greater importance to improve predictability of these events. Potential sources of prediction skill for above-average monthly extreme (and total) rainfall were investigated. SSTs were regressed on to EOT time series with varying lead times. Several warm-season EOTs of both extreme and total rainfall, such as December extreme rainfall EOT1, have concurrent patterns of regression coefficients with strong ENSO signatures in the Pacific Ocean (Fig. 71). Regressing SSTs from previous months on to December EOT1, thus introducing a lag, shows predictability from the equatorial Pacific decreasing as the lag increases (Fig. 7). Extending the lag to months 

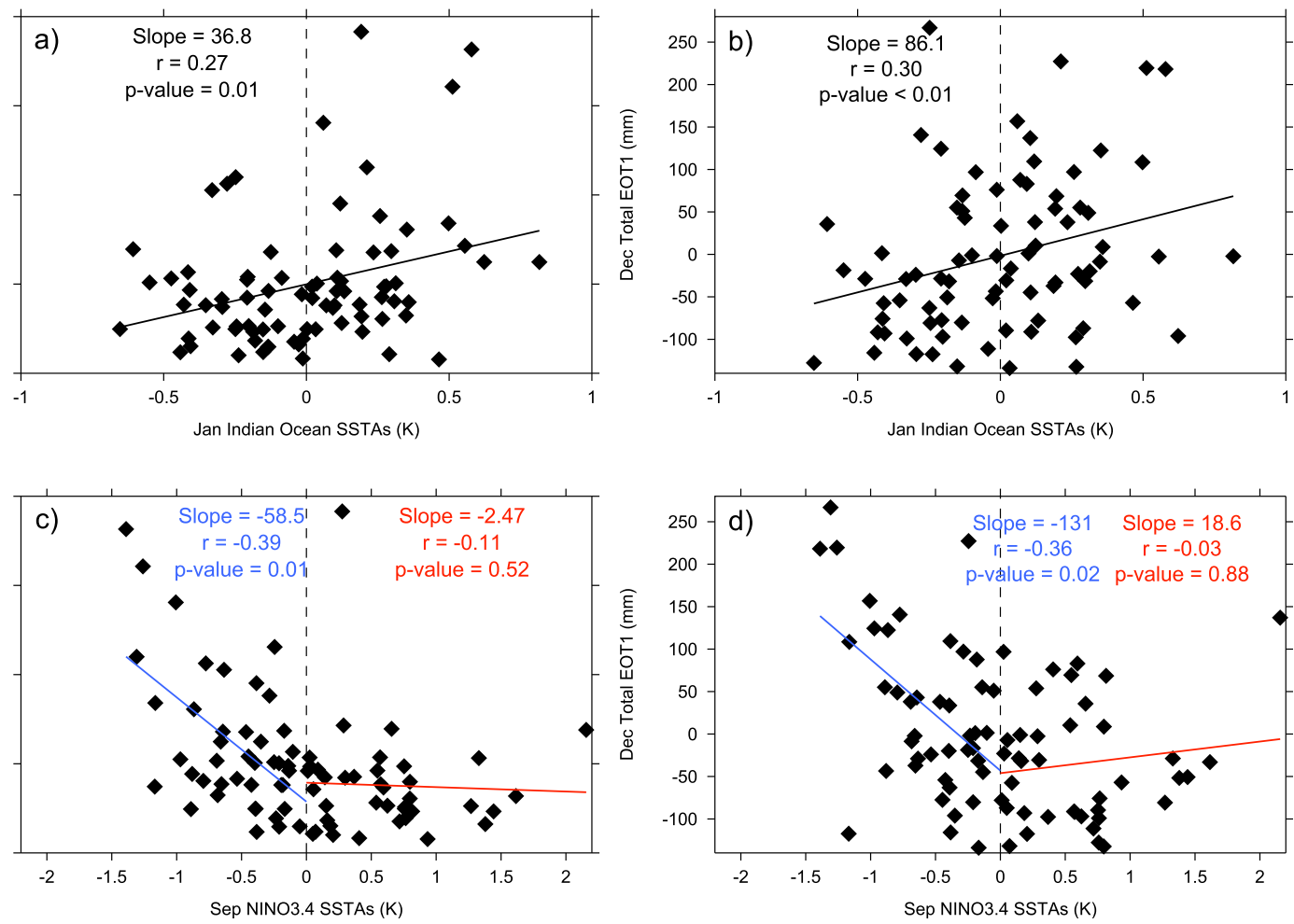

FIG. 8. Scatterplots of January equatorial Indian Ocean SST anomalies vs (a) December Rx5day EOT1 and (b) December total EOT1. Lines of best fit (black solid) are shown across all SST anomalies with slope, correlation coefficient, and $p$ value. Scatterplots of September Niño-3.4 SST anomalies vs (c) December Rx5day EOT1 and (d) December total EOT1. Lines of best fit are shown for negative (blue) and positive (red) SST anomalies with slope, rank correlation coefficient, and $p$ value.

prior to the "predictability barrier" of April-June (e.g., Webster and Hoyos 2010) causes the SST signature in the Pacific to largely disappear. However, a potential source of predictability is observed in the Indian Ocean using SST fields from January to March (i.e., 9-11 months in advance). Basinwide warming in the Indian Ocean during one warm season is related to above-average rainfall in parts of Queensland the following warm season. Averaging January SSTs over the box in Fig. 7a and correlating with December extreme rainfall EOT1 (11 months later) gives a correlation coefficient of 0.27 ( 0.30 for total rainfall). Scatterplots of January Indian Ocean SSTs and December extreme and total rainfall EOT1 (Figs. 8a,b) show large spread in the relationship but a clear tendency for a warmer Indian Ocean in January to relate to greater extreme and total rainfall in December. The lagged response of northern Australian rainfall to Indian Ocean warming was previously observed by Taschetto et al. (2011) and may be related to the IOD influence on ENSO more than 12 months in advance (Izumo et al. 2010). Here it is shown that the leading patterns of variability in extreme rainfall in Australia in December have a source of predictability arising from basinwide Indian Ocean warming from the previous warm season.

Equatorial Pacific Ocean SSTs are related to December extreme and total rainfall at shorter lead times. Scatterplots of September Niño-3.4 region SSTs and December extreme and total rainfall EOT1 (Figs. 8c,d) point to potential predictability of high extreme and total rainfall amounts related to emerging La Niña conditions at a lead time of 3 months. SST anomalies in the Niño-3.4 region are significantly correlated even a few months apart and this is likely to be behind the predictability at 3 months lead time (e.g., Jourdain et al. 2013). These potential predictability sources may aid in the forecasting of heavy summer rainfall in Queensland. Although, noise in SST relationships with rainfall points to limits in the predictability of monthly extreme and total rainfall.

There is an asymmetry in the ENSO relationship with warm-season extreme and total rainfall (King et al. 2013a; Cai et al. 2010; Power et al. 2006). This is reflected in concurrent SST regressions onto December extreme rainfall EOT1 for wetter-than-average and drier-thanaverage December Rx5day values separately (Figs. 9l, 101). There is greater potential for predictability of very wet 

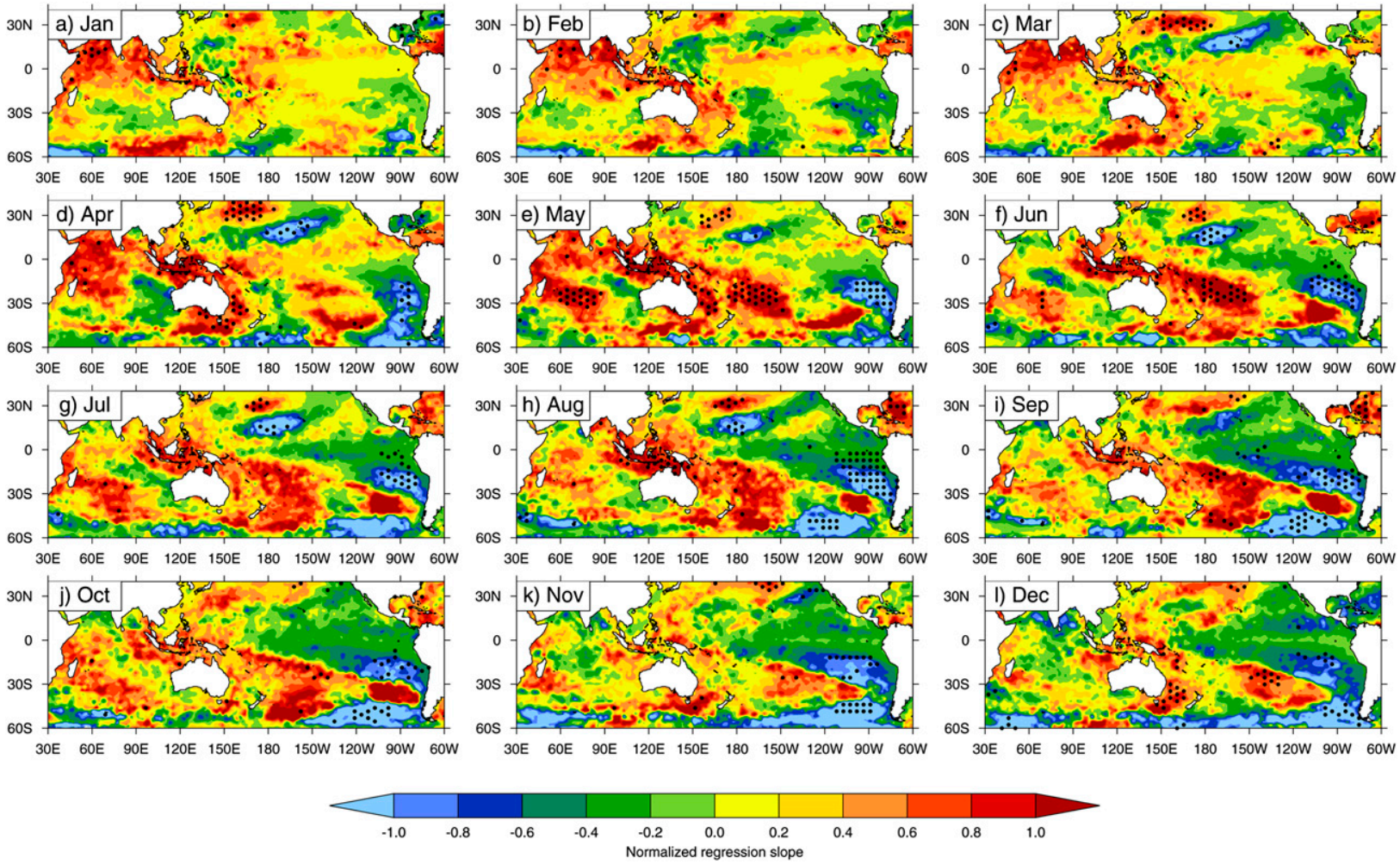

FIG. 9. Maps of SSTs from each calendar month (a)-(1) from January to December regressed on to December Rx5day EOT1 for wetter-than-average December Rx5day values only. Stippling indicates 5\% significance of the correlation between SSTs and the EOT.

extremes in Decembers from Pacific SSTs (Fig. 9) than there is of very dry December extremes (Fig. 10). This has important implications for the seasonal forecasting of flood and drought events. There is less of a nonlinearity in the relationship between December extreme rainfall EOT1 and Indian Ocean SSTs from the previous warm season (Figs. 9, 10). These results also extend to mean rainfall (Figs. S5 and S6 in the supplementary material).

There is lower potential for predictability of January and February leading EOTs of extreme and total rainfall as SST relationships with these time series are weaker (not shown). This is likely related to their locations tending to be farther west and in more inland areas (Fig. S2).

For some warm-season extreme rainfall patterns, particularly in December, there are sources of potential prediction skill arising from Pacific Ocean SSTs a few months in advance and Indian Ocean SSTs up to a year ahead. This potential for predictability extends to total rainfall patterns and could aid in the forecasting of heavy rainfall in northeastern Australia. In general, however, strong predictability of extreme and total rainfall is not observed and there is high noise in lagged SST relationships with EOTs.

\section{Discussion and conclusions}

This study presents an application of an EOT decomposition method to Australian extreme (and mean) rainfall for the investigation of climate drivers and their relative roles in the continent's climate. Use of this method sheds new light on extreme rainfall patterns, their drivers, and the predictability of extreme events.

A number of features are striking from examining the EOTs and their various relationships. The locations of extreme rainfall EOTs differ from those of mean rainfall in the cool season considerably more than in the warm season. The leading EOTs of extreme rainfall tend to be located farther north during austral winter than the EOTs of mean rainfall. This reflects the differences in weather systems affecting Australia between the warm and cool seasons. During the winter, midlatitude synoptic-scale systems pass across southern Australia bringing frontal rainfall over a large area. This has a strong effect on the spatial distribution of total rainfall. However, these frontal systems have less impact on the extreme rainfall index and result in small Rx5day values in many areas of southern Australia. 

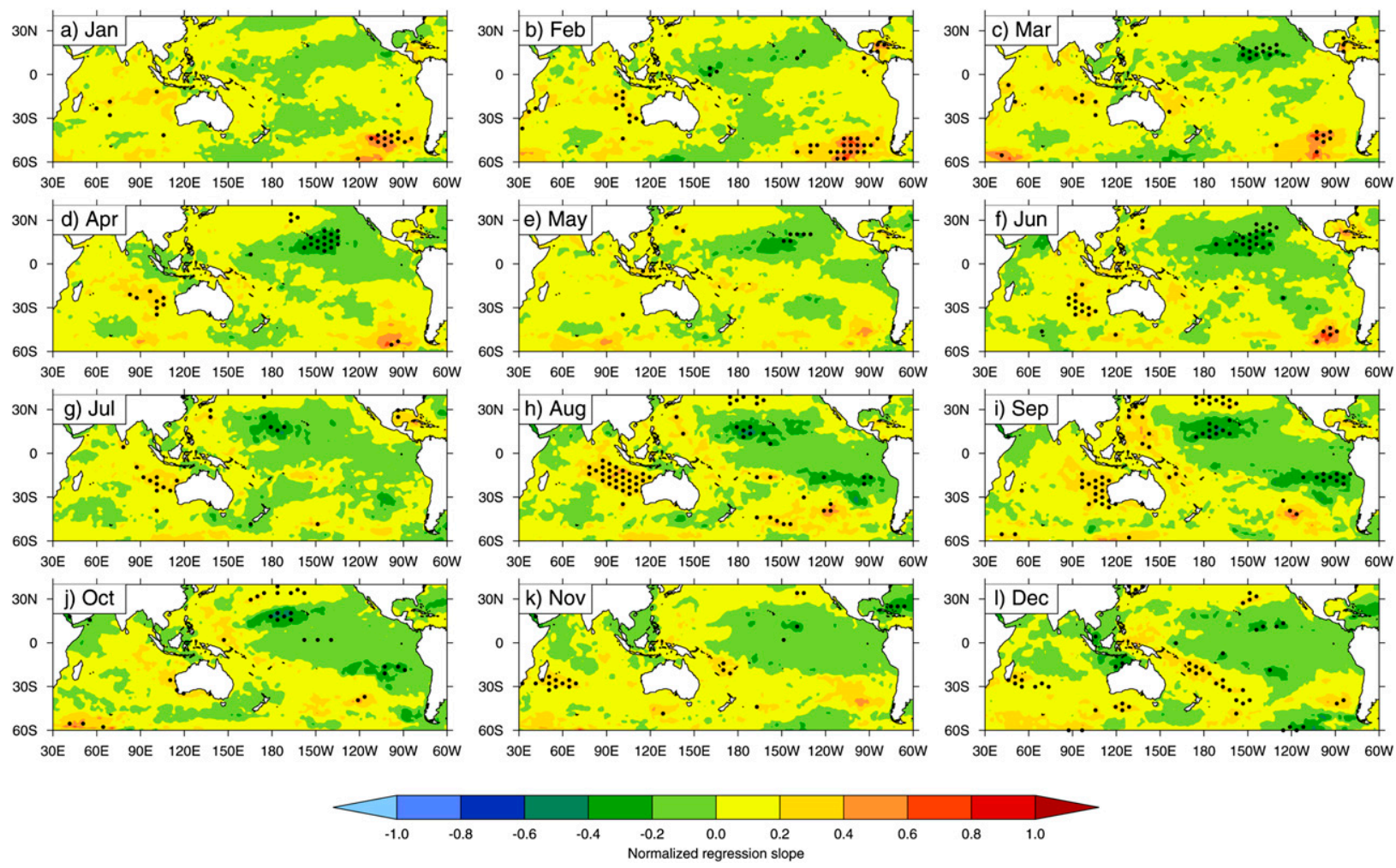

FIG. 10. As in Fig. 9, but for drier-than-average December Rx5day values only.

The predominance of ENSO as a driver of warmseason extreme rainfall variability in eastern Australia is clear, both from EOT relationships with the SOI and Niño-3.4 index and through examining fields from the 20CR. The SAM and IOD both have weaker roles. Blocking and the subtropical ridge strongly influence total rainfall, particularly during the cool season in southern and eastern Australia. Relationships with extreme rainfall tend to be weaker because of the locations of the Rx5day EOTs being farther north.

Several of the extreme rainfall EOTs are strongly related to local weather systems. Tropical cyclones affect warm-season EOTs in the north of the continent and east coast lows influence cool-season EOTs in the southeast. The EOTs that exhibit east coast low-like patterns have consistent atmospheric features: often an anomalous anticyclone to the south and associated onshore moist flow along the coastal fringe.

Warm-season EOTs are more closely related to SSTs than EOTs during the cool season. The SST fields associated with the leading December EOTs during the austral summer have ENSO-like SST patterns in the Pacific. Potential sources of prediction skill have been identified for above-average monthly rainfall and extreme rainfall through Pacific Ocean SSTs several months in advance and also Indian Ocean basinwide warming up to a year ahead. The Pacific conditions provide more information on how much wetter-than-average conditions could be than on how much drier-than-average they might be. On the other hand, the relationship between Indian Ocean SSTs and rainfall up to a year later is more linear.

In summary, this study uses a statistical decomposition of rainfall fields to show that extreme rainfall variability in Australia can be related to remote and local drivers as well as large-scale weather systems. The drivers of extreme rainfall variability are more similar to drivers of total rainfall in the warm season than the cool season. Extratropical climate drivers, such as blocking and the subtropical ridge, have weaker relationships with extreme rainfall than mean rainfall. There are potential sources of prediction skill for the most prominent modes of warm-season extreme rainfall variability arising from the Pacific and Indian Oceans as much as a year in advance.

Acknowledgments. We thank the editor for handling our submission and we thank Milton Speer and two anonymous reviewers for their helpful and constructive comments, which have improved this manuscript. Andrew 
King and Lisa Alexander were supported by Australian Research Council Grant CE110001028. Markus Donat was supported by Australian Research Council Grant LP100200690. Nicolas Jourdain was funded by Australian Research Council Grant DP110100601. Nicholas Klingaman was funded by the U.K. National Centre for Atmospheric Science, a Natural Environment Research Council collaborative center, under Contract R8/H12/83/001. We thank the Bureau of Meteorology, the Bureau of Rural Sciences, and CSIRO for providing the Australian Water Availability Project data. The Twentieth Century Reanalysis V2 data were provided by the NOAA/OAR/ ESRL PSD, Boulder, Colorado, from their website (at http://www.esrl.noaa.gov/psd/). Support for the Twentieth Century Reanalysis Project dataset is provided by the U.S. Department of Energy Office of Science Innovative and Novel Computational Impact on Theory and Experiment (DOE INCITE) program and Office of Biological and Environmental Research (BER) and by the National Oceanic and Atmospheric Administration Climate Program Office. HadISST SSTs were provided by the Met Office. IBTrACS data were provided by the National Climatic Data Center.

\section{REFERENCES}

Alexander, L. V., P. Hope, D. Collins, B. Trewin, A. Lynch, and N. Nicholls, 2007: Trends in Australia's climate means and extremes: A global context. Aust. Meteor. Mag., 56, 1-18.

Allan, R., 1988: El Niño-Southern Oscillation influences in the Australasian region. Prog. Phys. Geogr., 12, 313-348, doi:10.1177/ 030913338801200301.

Ashcroft, L., D. J. Karoly, and J. Gergis, 2014: Southeastern Australian climate variability 1860-2009: A multivariate analysis. Int. J. Climatol., 34, 1928-1944, doi:10.1002/joc.3812.

Brown, J. R., S. B. Power, F. P. Delage, R. A. Colman, A. F. Moise, and B. F. Murphy, 2011: Evaluation of the South Pacific convergence zone in IPCC AR4 climate model simulations of the twentieth century. J. Climate, 24, 1565-1582, doi:10.1175/ 2010JCLI3942.1.

Cai, W., and T. Cowan, 2006: SAM and regional rainfall in IPCC AR4 models: Can anthropogenic forcing account for southwest Western Australian winter rainfall reduction? Geophys. Res. Lett., 33, L24708, doi:10.1029/2006GL028037.

_ , P. van Rensch, T. Cowan, and A. Sullivan, 2010: Asymmetry in ENSO teleconnection with regional rainfall, its multidecadal variability, and impact. J. Climate, 23, 4944-4955, doi:10.1175/2010JCLI3501.1.

,$- \ldots$, and,- 2011 : Influence of global-scale variability on the subtropical ridge over southeast Australia. J. Climate, 24, 6035-6053, doi:10.1175/2011JCLI4149.1.

Compo, G. P., and Coauthors, 2011: The Twentieth Century Reanalysis project. Quart. J. Roy. Meteor. Soc., 137, 1-28, doi:10.1002/qj.776.

Cowan, T., P. van Rensch, A. Purich, and W. Cai, 2013: The association of tropical and extratropical climate modes to atmospheric blocking across southeastern Australia. J. Climate, 26, 7555-7569, doi:10.1175/JCLI-D-12-00781.1.
Evans, J. P., and I. Boyer-Souchet, 2012: Local sea surface temperatures add to extreme precipitation in northeast Australia during La Niña. Geophys. Res. Lett., 39, L10803, doi:10.1029/ 2012GL052014.

Feng, J., J. Li, and Y. Li, 2010: Is there a relationship between the SAM and southwest Western Australian winter rainfall? J. Climate, 23, 6082-6089, doi:10.1175/2010JCLI3667.1.

Gallant, A. J. E., K. J. Hennessy, and J. Risbey, 2007: Trends in rainfall indices for six Australian regions: 1910-2005. Aust. Meteor. Mag., 56, 223-239.

, A. S. Kiem, D. C. Verdon-Kidd, R. C. Stone, and D. J. Karoly, 2012: Understanding hydroclimate processes in the MurrayDarling Basin for natural resources management. Hydrol. Earth Syst. Sci., 16, 2049-2068, doi:10.5194/hess-16-2049-2012.

Gong, D., and S. Wang, 1999: Definition of Antarctic Oscillation index. Geophys. Res. Lett., 26, 459-462, doi:10.1029/1999GL900003.

Haylock, M., and N. Nicholls, 2000: Trends in extreme rainfall indices for an updated high quality dataset for Australia, 1910-1998. Int. J. Climatol., 20, 1533-1541, doi:10.1002/ 1097-0088(20001115)20:13<1533::AID-JOC586>3.0.CO;2-J.

Hendon, H. H., E.-P. Lim, J. M. Arblaster, and D. L. T. Anderson, 2014: Causes and predictability of the record wet east Australian spring 2010. Climate Dyn., 42, 1155-1174, doi:10.1007/ s00382-013-1700-5.

Holland, G. J., 1986: Interannual variability of the Australian summer monsoon at Darwin: 1952-82. Mon. Wea. Rev., 114, 594-604, doi:10.1175/1520-0493(1986)114<0594:IVOTAS > 2.0.CO;2.

Izumo, T., and Coauthors, 2010: Influence of the state of the Indian Ocean dipole on the following year's El Niño. Nat. Geosci., 3, 168-172, doi:10.1038/ngeo760.

Jeffrey, S. J., J. O. Carter, K. B. Moodie, and A. R. Beswick, 2001: Using spatial interpolation to construct a comprehensive archive of Australian climate data. Environ. Modell. Software, 16, 309-330, doi:10.1016/S1364-8152(01)00008-1.

Jones, D. A., W. Wang, and R. Fawcett, 2009: High-quality spatial climate data-sets for Australia. Aust. Meteor. Oceanogr. J., 58, 233-248.

Jourdain, N. C., A. S. Gupta, A. S. Taschetto, C. C. Ummenhofer, A. F. Moise, and K. Ashok, 2013: The Indo-Australian monsoon and its relationship to ENSO and IOD in reanalysis data and the CMIP3/CMIP5 simulations. Climate Dyn., 41, 3073 3102, doi:10.1007/s00382-013-1676-1.

Kidston, J., J. A. Renwick, and J. McGregor, 2009: Hemisphericscale seasonality of the southern annular mode and impacts on the climate of New Zealand. J. Climate, 22, 4759-4770, doi:10.1175/2009JCLI2640.1.

King, A. D., L. V. Alexander, and M. G. Donat, 2013a: Asymmetry in the response of eastern Australia extreme rainfall to lowfrequency Pacific variability. Geophys. Res. Lett., 40, 22712277, doi:10.1002/grl.50427.

,-- , and $-2013 \mathrm{~b}$ : The efficacy of using gridded data to examine extreme rainfall characteristics: A case study for Australia. Int. J. Climatol., 33, 2376-2387, doi:10.1002/joc.3588.

_ S. C. Lewis, S. E. Perkins, L. V. Alexander, M. G. Donat, D. J. Karoly, and M. T. Black, 2013c: Limited evidence of anthropogenic influence on the 2011-12 extreme rainfall over southeast Australia [in "Explaining Extreme Events of 2012 from a Climate Perspective"]. Bull. Amer. Meteor. Soc., 94 (9), S55-S58.

Klingaman, N. P., S. J. Woolnough, and J. Syktus, 2013: On the drivers of inter-annual and decadal rainfall variability in Queensland, Australia. Int. J. Climatol., 33, 2413-2430, doi:10.1002/joc.3593.

Knapp, K. R., M. C. Kruk, D. H. Levinson, H. J. Diamond, and C. J. Neumann, 2010: The International Best Track Archive 
for Climate Stewardship (IBTrACS): Unifying tropical cyclone data. Bull. Amer. Meteor. Soc., 91, 363-376, doi:10.1175/ 2009BAMS2755.1.

Larsen, S. H., and N. Nicholls, 2009: Southern Australian rainfall and the subtropical ridge: Variations, interrelationships, and trends. Geophys. Res. Lett., 36, L08708, doi:10.1029/2009GL037786.

Lavender, S. L., and D. J. Abbs, 2013: Trends in Australian rainfall: Contribution of tropical cyclones and closed lows. Climate Dyn., 40, 317-326, doi:10.1007/s00382-012-1566-y.

Madden, R. A., and P. Julian, 1971: Detection of a 40-50 day oscillation in the zonal wind in the tropical Pacific. J. Atmos. Sci., 28, 702-708, doi:10.1175/1520-0469(1971)028<0702: DOADOI $>2.0 . \mathrm{CO} ; 2$.

Maher, P., and S. C. Sherwood, 2014: Disentangling the multiple sources of large-scale variability in Australian wintertime precipitation. J. Climate, doi:10.1175/JCLI-D-13-00659.1, in press.

Marshall, G., 2003: Trends in the southern annular mode from observations and reanalyses. J. Climate, 16, 4134-4143, doi:10.1175/1520-0442(2003)016<4134:TITSAM >2.0.CO;2.

McBride, J. L., and N. Nicholls, 1983: Seasonal relationships between Australian rainfall and the Southern Oscillation. Mon. Wea. Rev., 111, 1998-2004, doi:10.1175/1520-0493(1983)111<1998: SRBARA $>2.0 . \mathrm{CO} ; 2$.

Meneghini, B., I. Simmonds, and I. N. Smith, 2007: Association between Australian rainfall and the southern annular mode. Int. J. Climatol., 27, 109-121, doi:10.1002/joc.1370.

Meyers, G., P. McIntosh, L. Pigot, and M. Pook, 2007: The years of El Niño, La Niña, and interactions with the tropical Indian Ocean. J. Climate, 20, 2872-2880, doi:10.1175/JCLI4152.1.

Min, S.-K., W. Cai, and P. Whetton, 2013: Influence of climate variability on seasonal extremes over Australia. J. Geophys. Res. Atmos., 118, 643-654, doi:10.1002/jgrd.50164.

Nicholls, N., B. Lavery, C. Frederiksen, W. Drosdowsky, and S. Torok, 1996: Recent apparent changes in relationships between the El Niño-Southern Oscillation and Australian rainfall and temperature. Geophys. Res. Lett., 23, 3357-3360, doi:10.1029/96GL03166.

—- W. Drosdowsky, and B. Lavery, 1997: Australian rainfall variability and change. Weather, 52, 66-71, doi:10.1002/ j.1477-8696.1997.tb06274.x.

Parker, D., C. Folland, A. Scaife, J. Knight, A. Colman, P. Baines, and B. Dong, 2007: Decadal to multidecadal variability and the climate change background. J. Geophys. Res., 112, D18115, doi:10.1029/2007JD008411.

Pook, M., and T. Gibson, 1999: Atmospheric blocking and storm tracks during SOP-1 of the FROST project. Aust. Meteor. Mag., 48, 51-60.

Power, S., M. Haylock, R. Colman, and X. Wang, 2006: The predictability of interdecadal changes in ENSO activity and ENSO teleconnections. J. Climate, 19, 4755-4771, doi:10.1175/ JCLI3868.1.

Rayner, N. A., D. E. Parker, E. B. Horton, C. K. Folland, L. V. Alexander, D. P. Rowell, E. C. Kent, and A. Kaplan, 2003: Global analyses of sea surface temperature, sea ice, and night marine air temperature since the late nineteenth century. J. Geophys. Res., 108, 4407, doi:10.1029/2002JD002670.
Risbey, J. S., M. J. Pook, P. C. McIntosh, M. C. Wheeler, and H. H. Hendon, 2009: On the remote drivers of rainfall variability in Australia. Mon. Wea. Rev., 137, 3233-3253, doi:10.1175/ 2009MWR2861.1.

_ , P. C. McIntosh, and M. J. Pook, 2013: Synoptic components of rainfall variability and trends in southeast Australia. Int. J. Climatol., 33, 2459-2472, doi:10.1002/joc.3597.

Saji, N. H., B. N. Goswami, P. N. Vinayachandran, and T. Yamagata, 1999: A dipole mode in the tropical Indian Ocean. Nature, 401, 360-363.

Smith, I., 2004: An assessment of recent trends in Australian rainfall. Aust. Meteor. Mag., 53, 163-173.

Speer, M. S., 2008: On the late twentieth century decrease in Australian east coast rainfall extremes. Atmos. Sci. Lett., 9, 160-170, doi:10.1002/asl.191.

_ , L. M. Leslie, and A. O. Fierro, 2011: Australian east coast rainfall decline related to large scale climate drivers. Climate Dyn., 36, 1419-1429, doi:10.1007/s00382-009-0726-1.

Taschetto, A. S., A. S. Gupta, H. H. Hendon, C. C. Ummenhofer, and M. H. England, 2011: The contribution of Indian Ocean sea surface temperature anomalies on Australian summer rainfall during El Niño events. J. Climate, 24, 3734-3747, doi:10.1175/2011JCLI3885.1.

Timbal, B., and W. Drosdowsky, 2013: The relationship between the decline of southeastern Australian rainfall and the strengthening of the subtropical ridge. Int. J. Climatol., 33, 1021-1034, doi:10.1002/joc.3492.

Trenberth, K., 1984: Signal versus noise in the Southern Oscillation. Mon. Wea. Rev., 112, 326-332, doi:10.1175/ 1520-0493(1984)112<0326:SVNITS > 2.0.CO;2.

Ummenhofer, C. C., M. H. England, P. C. McIntosh, G. A. Meyers, M. J. Pook, J. S. Risbey, A. S. Gupta, and A. S. Taschetto, 2009: What causes southeast Australia's worst droughts? Geophys. Res. Lett., 36, L04706, doi:10.1029/2008GL036801.

_ and Coauthors, 2011: Indian and Pacific Ocean influences on southeast Australian drought and soil moisture. J. Climate, 24, 1313-1336, doi:10.1175/2010JCLI3475.1.

Van den Dool, H. M., S. Saha, and A. Johansson, 2000: Empirical orthogonal teleconnections. J. Climate, 13, 1421-1435, doi:10.1175/1520-0442(2000)013<1421:EOT>2.0.CO;2.

Vincent, E. M., M. Lengaigne, C. E. Menkes, N. C. Jourdain, P. Marchesiello, and G. Madec, 2011: Interannual variability of the South Pacific Convergence Zone and implications for tropical cyclone genesis. Climate Dyn., 36, 1881-1896, doi:10.1007/s00382-009-0716-3.

Webster, P. J., and C. D. Hoyos, 2010: Beyond the spring barrier? Nat. Geosci., 3, 152-153, doi:10.1038/ngeo800.

Whan, K., B. Timbal, and J. Lindesay, 2014: Linear and nonlinear statistical analysis of the impact of sub-tropical ridge intensity and position on south-east Australian rainfall. Int. J. Climatol., 34, 362-342, doi:10.1002/joc.3689.

Zhang, X., L. Alexander, G. C. Hegerl, P. Jones, A. K. Tank, T. C. Peterson, B. Trewin, and F. W. Zwiers, 2011: Indices for monitoring changes in extremes based on daily temperature and precipitation data. Wiley Interdiscip. Rev.: Climate Change, $\mathbf{2}$, 851-870, doi:10.1002/wcc.147. 